\title{
Breve ensaio sobre o tempo, o sujeito e os modos de olhar para a história: Foucault e Cortázar
}

\author{
Bruno Pastoriza* \\ José Claudio Del Pino**
}

\section{Resumo}

Pautado na literatura fantástica de Julio Cortázar e na proposta de história efetiva de Michel Foucault, este ensaio busca trazer um modo diferente de pensarmos as relações entre o sujeito e o tempo da história como elementos dos estudos em Educação. Iniciando com um conto cortazariano, evidencia-se a possibilidade de outro modo de ler o tempo no qual o conto se desdobra, bem como o próprio sujeito nele constituído. A partir dessas relações, articulam-se as propostas foucaultianas de afastamento dos duplos referentes ao sujeito e da concepção de tempo como motor da história. Ambos os autores são utilizados então para problematizar o campo das pesquisas em Educação e seus modos de compreender o tempo e o sujeito, que, pelo olhar desses dois autores, podem ser reconstruídos.

Palavras-chave: Literatura. Educação. Saber.

* Doutor em Educação em Ciências pela Universidade Federal do Rio Grande do Sul (UFRGS). Professor do Centro de Ciências Químicas, Farmacêuticas e de Alimentos da Universidade Federal de Pelotas (UFPel). bspastoriza@gmail.com.

** Doutor em Engenharia de Biomassa pela Universidade Federal do Rio Grande do Sul (UFRGS). Professor do Programa de Pós-Graduação em Educação em Ciêncais: Química da Vida e Saúde da Universidade Federal do Rio Grande do Sul (UFRGS).delpinojc@yahoo.com.br. 


\section{Introdução}

Certa vez, em um de seus textos, Gilles Deleuze (2005, p. 131) trouxe a noção de que "Ciência e poesia são, igualmente, saber”. Assim, é com esta ideia que buscaremos desenvolver este ensaio. Entendendo que a frase proferida por esse autor refere-se aos estudos de Michel Foucault e ao reconhecimento de seu modo particular de trabalho, neste ensaio temos como objetivo traçar uma íntima relação entre a produção de saberes do campo da literatura e do campo das ciências, utilizando-a para pensarmos as pesquisas em Educação e o referencial foucaultiano de análise. Desse modo, trabalharemos aqui com a proposta de modificação do olhar acerca do sujeito e do tempo da história, que sistematicamente tomamos como base para a constituição de nossas pesquisas no campo educacional, com vistas a trazer outras potencialidades às investigações realizadas.

Para empreender tal tarefa, buscaremos na discussão de um conto de Julio Cortázar expandir a noção de realidade que podemos trabalhar com a literatura fantástica e, a partir disso, buscaremos associar essas possibilidades aos trabalhos de Michel Foucault, o qual tem sido, ultimamente, muito utilizado nas pesquisas do campo educacional, como bem nos aponta Gallo (2014) com a discussão acerca do "Efeito Foucault" na Educação. Enquanto com Cortázar apontaremos uma presença de outra forma de sujeito e de um desdobrar de tempo diferentes daqueles seguidamente empregados nos estudos da área que problematizamos, com Foucault buscaremos, de modo concomitante, uma teorização e pluralização dessas ideias a partir daquilo que o autor denomina de história efetiva. Com o encontro entre ambos, buscamos, ao final do texto, trabalhar suas ideias em um conjunto de relações e possibilidades de problematizar os estudos em Educação.

\section{Uma História Fantástica}

Iniciemos com um conto de Cortázar recontado, de modo resumido, por ele mesmo ${ }^{1}$ :

Un hombre - en este caso soy yo - tiene un accidente de moto, lo llevan al hospital, todo lo que ustedes saben. Se duerme y entra en la situación de ser un indio mexicano que está huyendo en plena noche porque lo persiguen y, como sucede en los sueños en que sabemos todo sin necesidad de explicaciones, yo, o sea el que está soñando, sabe que es un indio de la tribu de los motecas, nombre que inventé y que un crítico pensó que se derivaba del hecho de que el 
protagonista tenía una motocicleta..., lo cual prueba los peligros de la pura inteligencia racional cuando busca asociaciones por ciertos medios. El moteca se siente perseguido por los aztecas que han entrado en ese período de su civilización que todos conocemos, la guerra florida: llega un momento en que para ofrecer sacrificios a sus dioses los aztecas salían a perseguir enemigos, los capturaban vivos, los envolvían en flores, los traían a Tenochtitlán, los guardaban en una mazmorra y el día de la fiesta del dios los subían a las pirámides y les arrancaban el corazón. Ustedes lo saben por los códices y por los cronistas: la guerra florida siempre me ha impresionado porque parece una cosa tan hermosa y tan pacífica capturar vivo el adversario, darle flores y traerlo de vuelta como en una fiesta. ¡Qué fiesta! Como es natural, el moteca sabe muy bien lo que le espera y huye desesperadamente, huye y siente cada vez más cerca a los perseguidores y entonces bruscamente se despierta. Claro, se despierta en el hospital en donde estaba: es el hombre que ha tenido el accidente. Se despierta con su pierna y su botella de agua y respira satisfecho al darse cuenta de que eso no era más que un sueño. Se vuelve a dormir y el sueño recomienza y está siempre perseguido y cada vez se le acercan más. Esta vez consigue despertar de nuevo pero ya es más difícil despertarse, es una especie de gran esfuerzo, él mismo no sabe cómo hace para salir de esa profundidad de la persecución y encontrarse de nuevo en el hospital. Entonces empieza a luchar contra el sueño pero tiene fiebre y está muy enfermo, muy débil, y se vuelve a dormir. Cuando se vuelve a dormir es el momento en que le echan un lazo y lo capturan, lo llevan a una mazmorra y lo ponen allí esperando el momento del sacrificio. Por última vez (...) consigue despertarse un momento; sí, alcanza a despertarse un momento (...) Se despierta y es como un desesperado deseo de poder tocar algo, de aferrarse a la realidad, porque se siente absorbido por esa pesadilla espantosa; pero todo se diluye y no consigue sujetar nada y se hunde otra vez en la pesadilla. Entonces entran los sacerdotes y lo empiezan a subir por los peldaños de la pirámide; en lo alto ve al sacrificador que lo está esperando con el cuchillo de jade o de obsidiana empapado de sangre y con un último esfuerzo de su voluntad trata de despertarse. En ese momento tiene la 
revelación, se da cuenta de que no se va a despertar, de que ésa es la realidad, que él es un hombre que soñó que vivía en una ciudad muy extraña con edificios altísimos, luces verdes y rojas, y que andaba en una especie de insecto de metal. Todo eso lo piensa mientras lo están subiendo para sacrificarlo (CORTÁZAR, 2013, p. 66-67).

A questão que nos coloca Cortázar neste conto em específico, sobre a qual vemos possibilidades para empreender um trabalho de pensamento, está no próprio desfecho da trama: seu fim estava interligado a acontecimentos que, em seu limite de sonho, poderiam se prolongar indefinidamente, mas que o autor resolve operar por cortes, determiná-los, separá-los. Isso implica conceber que esse tempo, que Cortázar nos conta em sua aula de literatura e em sua história, faz algo mais do que entremear a cena apresentada; esse tempo nos permite questionar os próprios arranjos que, a partir do texto e do cenário constituído, dispomos em nossas investigações, em nossas análises, em nossas falas, em cada recorte de pesquisa.

Se aceitarmos que todo o desdobramento inicial do conto - que se refere a um acidente de moto sofrido pela personagem após tentar desviar de uma senhora que atravessa a rua enquanto o sinal estava aberto aos motoristas - esteja ocorrendo simultaneamente à perseguição do índio moteca pela tribo asteca, cuja primeira parte nada mais é do que algo assumido a partir de um sonho produzido na segunda, perceberemos a questão de uma realidade multiplicada. Acerca dela, Julio Cortázar comenta que desde há muito apresentava uma visão particular dessa potencialidade proporcionada pelo fantástico:

[...] desde muy niño lo fantástico no era para mí lo que la gente considera fantástico; para mí era una forma de la realidad que en determinadas circunstancias se podía manifestar, a mí o a otros, a través de un libro o un suceso, pero no era un escándalo dentro de una realidad establecida. Me di cuenta de que yo vivía sin haberlo sabido en una familiaridad total con lo fantástico porque me parecía tan aceptable, posible y real como el hecho de tomar una sopa a las ocho de la noche; con lo cual (y esto se lo pude decir a un crítico que se negaba a entender cosas evidentes) creo que yo era ya en esa época [ele se refere aqui a sua infância] profundamente realista, más realista que los realistas puesto que los realistas como mi amigo aceptaban la realidad hasta un cierto punto y después todo lo demás era fantástico. Yo aceptaba una realidad más grande, más elástica, más expandida, donde entraba todo (CORTÁZAR, 2013, p. 50).

Nesse sentido, com Cortázar nos apropriamos da noção de multiplicação da realidade, na qual o fantástico poderia ser apenas um jogo de acontecimentos, casos, acasos, processos, etc. que estivessem fora daquilo tomado como real. Com esse autor, nós percebemos a possibilidade de pluralização de um espaço em função daquilo que podemos significar sobre ele; do que podemos estabelecer; das relações 
possíveis de formar. Como Cortázar nos apresenta essa multiplicação? Simplesmente operando de outro modo com a noção do sujeito da história. A esse respeito, é Cortázar (2013, p. 56) quem nos encaminha um pensamento: "Escribí el cuento con la impresión (y digo impresión porque nunca hay explicaciones en estas cosas), con la sensación de que en algún momento hay un desdoblamiento del tiempo, lo cual significa un desdoblamiento del personaje”. Duplo desdobramento: do sujeito e do tempo da história. Analisemos ambos e estabeleçamos algumas relações entre o conto recontado e esse posicionamento indicado por Cortázar com os trabalhos de Michel Foucault e, a partir disso, busquemos as interrelações que tanto nós quanto outros colegas podemos trazer em nossos trabalhos e pesquisas em Educação.

\section{O Sujeito Da História}

Tomando por recorte esse conto, é possível inferir que Cortázar se aproxima de Foucault quando todos os elementos que constituíam a verdade do personagem são pulverizados no espaço metafórico de um sonho-realidade. Se, em uma primeira leitura, podemos pôr em discussão a existência ou não da moto, se há ou não há um inseto de metal, não podemos, mais densamente, deixar de marcar a ideia de que todas as medidas anteriormente formadas, ao final do conto, já não têm mais o mesmo peso inicial. Aproximamos Foucault de Cortázar quando não temos mais uma história real, senão uma ficção $^{2}$, que pode ser entendida como uma dissociação sistemática da identidade do personagem da história:

Pois essa identidade, bastante fraca contudo, que tentamos assegurar e reunir sob uma máscara, é apenas uma paródia: o plural a habita, almas inumeráveis nela disputam; os sistemas se entrecruzam e se dominam uns aos outros. Quando estudamos a história nos sentimos "felizes, ao contrário dos metafísicos, de abrigar em si não uma alma imortal, mas muitas almas mortais" (Nietzsche, O andarilho e sua sombra, §17). (FOUCAULT, 2013a, p. 82).

Não mais $o$ personagem que a história de Cortázar nos coloca em evidência, mas determinado personagem possível. Não mais $o$ sujeito de alma imortal, mas uma pluralidade de sujeitos mortais. Foucault, inspirado em Nietzsche, apresenta-nos um sujeito humano com prazo de validade, ou seja, não mais aquele expresso pelo cogito, aquele que pronunciava a si como um duplo empíricotranscendental, que partia da relação cógito-impensado ou que se pautava na noção de recuo-retorno da origem, mas, sim, aquele que se vê enquanto multiplicidade, fragmentariedade e finitude. Esse sujeito que vemos percorrer as histórias foucaultiana e cortazariana seria, então, não mais aquele que sempre 
existiu, mas, senão e apenas, "um efeito de superfície, é espuma que reverbera a força das ondas" (BRANCO, 2001, p. 239). Não há como tomar, então, a existência de um e mesmo personagem que atravesse soberanamente todo o campo da história contada; não há um personagem, mas personagens desdobrados, multiplicados, atravessados e criados pela narração e pelos acontecimentos do/no conto. E que isso não seja entendido como a operação de um homem que foi duplicado em um momento e cujo seu complemento estaria em outro sujeito - como, por exemplo, na história de Saramago (2002). Temos, isso sim, diferentes personagens, com histórias distintas, experiências particulares, mundos diferentes e existências descontínuas.

Com Foucault, passamos a entender que "uma coisa em todo o caso é certa: é que o homem não é o mais velho problema nem o mais constante que se tenha colocado ao saber humano" (FOUCAULT, 1987, p. 403). Isso nos leva a uma apropriação das ideias foucaultianas em conjunto com a problematização cortazariana, de modo que aquele vivente da motocicleta e o da tribo moteca nos colocam em um ponto de inflexão de uma curva que representaria a leitura habitual. Acerca desta, Foucault (2013b, p. 43) nos indicará que "é preciso se livrar do sujeito constituinte, livrar-se do próprio sujeito, isto é, chegar a uma análise que possa dar conta da constituição do sujeito na trama histórica", ou melhor, no caso de Cortázar, do conto.

Assumir esse modo de olhar para a história é compreendê-la em sua dispersão, diferença, mutabilidade. Segundo Foucault, essa forma de fazer história, que ele chama de efetiva, contrapõe-se às formas clássicas de se voltar a uma história com base na origem, nas continuidades. "A história 'efetiva' se distingue daquela dos historiadores pelo fato de que ela não se apoia em nenhuma constância: nada no homem - nem mesmo seu corpo - é bastante fixo para compreender outros homens e se reconhecer neles" (FOUCAULT, 2013a, p. 72). E é nessa conjuntura que ele institui um dos significados da vida humana: "não aceitar nada mais como definitivo, intocável, óbvio ou imóvel" (FOUCAULT, 2012a, p. 137), e com isso retornamos ao conto de Cortázar e sua localização no fantástico. Como já expresso, Cortázar compreendia a realidade de modo ampliado, sendo o fantástico dos outros uma simples possibilidade para ele. Dele a Foucault, muitas aproximações, mas cuja ênfase, aqui, recai, principalmente, sobre essa aposta na mudança e no possível. Nesse conjunto, Oliveira (2008, p. 180) propõe uma frase interessante, que vemos aplicável tanto a Foucault quanto a Cortázar: “as torções propostas por sua analítica desorientam-nos em um terreno onde desaparece a reconfortante ideia de permanência". Índio e motociclista; nem um, nem outro, e ambos presentes em uma história fantástica como a que Foucault nos conta e faz contar. 
Enfocando no sujeito, no que se refere ao homem, Foucault é claro em termos de sua invenção. Ele busca liberar sua filosofia do tema antropológico, pois, se as discussões acerca dele desaparecessem assim como surgiram, "então se pode apostar que o homem se desvaneceria, como, na orla do mar, um rosto de areia" (FOUCAULT, 1987, p. 404). Contudo é importante destacar que isso não implica dizer que não haja mais o homem, nem mesmo que ele seja retirado do quadro que até então se estabelecia lembremos do quadro de Velásquez e a representação da representação, na qual esse sujeito não pode ser de lá retirado (DREYFUS; RABINOW, 1995; FOUCAULT, 1987). Ao contrário, o recurso antiantropológico se desenvolve e fundamenta na forma como se produz o conhecimento em uma nova história: não mais o recurso aos duplos, mas uma analítica dos discursos; não mais a preocupação com o sentido e com a verdade, mas, sim e principalmente, com os jogos e regras que os instituem. E é na fuga, na negação, na contrariedade às categorias antropológicas que Foucault empreende, básica e resumidamente, em determinado momento de suas pesquisas, dois movimentos. Um analisará o discurso do qual busca um afastamento, qual seja: as ciências do homem. O outro se pauta na concepção de novas categorias analíticas, que passarão a ser os objetos, os sujeitos e suas modalidades, os conceitos, as estratégias, e não mais as proposições, a significação, etc.

Tirando o homem transcendente do centro da cena, aquele que pensa e existe, Foucault nos aponta um trabalho que pretende desenvolver sem recorrer às noções de trancendência da razão, do sujeito, da dialética, etc., possibilitando a realização de trabalhos que, inclusive, discutirão as sujeições feitas a esse homem que se pensava liberto de si mesmo (FOUCAULT, 1984, 1988, 1999, 2012b). Conforme Veiga-Neto (1996, p. 29), isso "tem efeitos devastadores na medida em que mudam as metodologias de análise, mudam as possibilidades de intervenção no mundo, mudam os problemas, mudam os processos, etc.". Talvez por isso se justifique a crítica maior que se faz Às Palavras e as Coisas (FOUCAULT, 1987), pois, se entendermos esse livro como uma prática libertária de uma filosofia para além dos pressupostos clássicos, que busca um pensamento além daquele de Kant e da compreensão dos limites de nosso conhecimento, a modificação nas formas de pensar e propor os problemas também se modifica - de um modo tão complexo que Foucault buscou organizá-los, mas longe de se volver a um estruturalismo.

De qualquer modo se trata de fazer da história um uso que a liberte para sempre do modelo, ao mesmo tempo, metafísico e antropológico da memória. Trata-se de fazer da história uma contra-memória e de desdobrar consequentemente toda uma outra forma do tempo. (FOUCAULT, 2013a, p. 80). 
E é dessa última consideração de Foucault acerca do tempo que voltamos ao conto de Cortázar, trazendo o segundo desdobramento apontado neste ensaio, qual seja, o que se refere ao tempo da história.

\section{O Tempo Da História}

O real ao qual Cortázar faz referência no conto não transita apenas pelos sujeitos que se constituem em sua trama, mas também necessita fundamentalmente de uma coordenada temporal na qual essa realidade se expressará - expressão que nos coloca em xeque com a nossa própria leitura da história; eis, novamente, o fantástico. Aqui percebemos mais uma articulação entre as propostas de Foucault e este conto de Cortázar: ambos nos põem em um ponto de instabilidade e de incerteza com os arranjos desse tempo, em uma possível posição de modificação e, mais especificamente no contexto da história que trazemos como exemplo e problematização, podemos observar que ambos os autores não se limitam ao dado ou àquilo que se naturaliza enquanto realidade e verdade ou o que ocorre em um passo imutável de tempo.

Quando embarcamos nessa história cortazariana, percebemos que transitamos em temporalidades totalmente diferentes e não intercambiáveis (embora articuláveis). Ao final da história, temos um tempo transcorrido durante dias, semanas, que rememora uma manhã, a leveza e o frescor do dia em que se montou na motocicleta e saiu-se ao prazer do vento até o momento do acidente; mas temos, também, outro tempo, que tem sua escala própria, que percorre também dias, mas que nos leva a perceber que a escala temporal anterior não passou de frações de tempo - as quais também não são especificadas e não nos permitem elaborar uma proporcionalidade entre elas e o tempo no qual se inserem.

De Cortázar a Foucault e de Foucault novamente a Cortázar percebemos uma grande aproximação na problematização do tempo da história. Este não é mais entendido enquanto motor desta; pelo contrário, ele se torna possível nas relações estabelecidas no próprio conto, com os personagens desdobrados e com as situações descritas, algo que nos remete à fala de Lyotard (apud Veiga-Neto, 1996, p. 51): “os nomes [assim como os tempos] não se apreendem sozinhos, apreendemse alojados em pequenas histórias". 
Não há mais como buscar o aquilo mesmo, não podemos retornar ao imediatamente anterior do conto. Em sua leitura, não podemos mais acreditar ou esperar uma essência, pois ela é quebrada, despedaçada e pulverizada no momento em que sonho, realidade, tempos e personagens se embaralham. Tais elementos formam um movimento que podemos tomar quase como um disparate: “Gosta-se de acreditar que as coisas no início se encontravam em estado de perfeição, que elas saíram brilhantes das mãos do criador, ou na luz sem sombra da primeira manhã” (FOUCAULT, 2013a, p. 59), e é esse próprio brilho que Cortázar, assim como Foucault, nos fazem ofuscar com as suas formas de contar a história, de organizar sua temporalidade, suas relações e seus sujeitos.

A literatura fantástica, de modo amplo, sistematicamente, permite-nos o afastamento de uma posição de conforto; uma suspensão daquilo que ora operaria enquanto lei natural ou verdade dada - e é por meio dessas suspensões, desses cortes que se diferenciam em temporalidades, relações e personagens, que entendemos haver fortes imbricamentos entre a literatura fantástica, a fastástica história que nos conta Foucault e a fantástica pesquisa que podemos empreender em vários campos; no caso deste ensaio, no campo da Educação. Se em um não há mais a história que se contava inicialmente (que não passava de sonho e que percebemos a partir das relações que estabelecemos com cada evento que ocorre, cada enunciado que surge), no outro temos a mesma suspensão: menos a história e mais uma história. Em ambos, não mais o dado de antemão, senão as relações construídas na trama. Com os dois autores, nada menos que o súbito sentimento de rir das solenidades da origem e de como tudo começou - e por que não realizar também isso em nossas pesquisas em Educação?

\section{Considerações Finais: Relações}

Um conto fantástico e uma fantástica história do presente. Dois modos de problematizar a realidade que não se limitam ao que ocorre, mas que seguem no rumo da possibilidade. Com Foucault e Cortázar somos impelidos a trocar de óculos para perceber, significar e compreender o que nos atravessa dia após dia. Isso não é diferente quando pensamos em nossas pesquisas no campo da Educação. Partindo das inspirações desses dois autores, surje o reconhecimento de diferentes possibilidades de olhar para os arranjos em que nos inserimos diariamente em nosso fazer Educação e em nossas pesquisas da área. Se nos pautarmos na Escola, perceberemos que ali ocorrem dinâmicas, conversas, ações, processos, etc., que muito podemos problematizar a partir de uma modificação na leitura que fazemos dos sujeitos que nesse espaço se constituem e do tempo que se desenvolve ali. 
Em um ensaio como este, temos por objetivo, então, convidar os colegas que, como nós, trabalham e pesquisam nesse espaço a tratá-lo como uma história que compomos, na qual tanto sujeito quanto tempo e efeitos são muito mais complexos e desdobram-se em um espaço muito mais amplo do que aquele pautado pela noção das continuidades, estabilidades e sequências. Se ambos os autores nos abrem possibilidades de contar uma história, de fazê-la transitar e constituir-se por meio de relações que podem, em muitos casos, retirar-nos de uma posição de conforto, utilizemos, pois, esse movimento a que eles (e outros mais) nos impelem para realizar nossas pesquisas. Com eles, podemos ser mobilizados a problematizar o sujeito aluno que constituímos. Os discursos que produzimos, as práticas que traçamos e outras ações têm por efeito a produção de sujeitos da Educação que, em dados momentos e perspectivas, são tomados como determinados, com características estabelecidas, e não a partir da sua potencialidade de ser construído ao longo da história que produzimos. De modo similar, o próprio tempo é tomado como passo imutável, sem referência às suas variações, como, por exemplo, os diferentes períodos de aprendizagens dos diversos alunos que se articulam conosco em nossas práticas. Neste caso, as temporalidades são tão dinâmicas quanto o espaço constituído nessa proposta foucaultiana de compreensão e produção da realidade (DELEUZE, 2005).

Complementarmente, evidenciamos que trabalhar com outra perspectiva acerca do tempo e do sujeito da Educação traz consigo outros elementos importantes a serem problematizados, como os conteúdos escolares (por exemplo, analisando seus efeitos de escolha, delimitação, apropriação e aprofundamento na constituição da trama histórica dos sujeitos que deles estão se apropriando), as práticas de sala de aula (afinal, assim como o conto de Cortázar, estabelecemos relações que não têm um fim determinado por aquilo que originou o processo ou, muito menos, que se espelhará no que já ocorreu, retornando à origem; portanto, práticas sempre produzindo e sendo produzidas); podemos repensar nossos papeis enquanto educadores, pesquisadores, sujeitos que estão constituindo essa história (pois em cada momento de nossa pesquisa no campo da Escola trazemos algum novo elemento cujo efeito pode modificar a trama, assim como o sonho do moteca modificou aquela do sujeito da moto), bem como podemos modificar o entendimento que temos dos outros sujeitos que nos acompanham nesse percurso (uma vez que, não havendo um ponto originário que exigirá sempre seu retorno ou, ainda, um cógito que nos determine os modos de conhecer, há sempre a possibilidade de mutação, de metamorfose, de clivagem total ou particial no modo como determinado sujeito da história vê a si, seu papel, o nosso papel, sua função no conto que compõe no ambiente educacional).

Quando trazemos neste ensaio Foucault e um conto de Cortázar juntos, como elementos problematizadores e como fonte de inspiração, buscamos marcar sua potencialidade de nos fazer 
transitar de histórias em histórias, de contos a cantos em que podemos descrever acontecimentos, relações, saberes, enunciados, discursos. Por meio destas descrições, relações e explicações, entendemos que podemos modificar tanto a nossa história quanto a própria história daquele local em que traçamos nossas vivências, não o tomando mais como dado, fixo, imutável, mas justamente por sua potência de constante modificação, ressignificação. Se Cortázar nos apresenta uma história localizada no fantástico, Foucault persegue o mesmo caminho, mas inversamente, pois parte de nossa localização no fantástico para, lá e a partir de lá, construir uma história, pois este autor faz uma história do presente e analisa as condições de possibilidade para seu surgimento - e esta não será nem mais nem menos real que outras, mas sempre mais uma história possível, sempre uma uma história de cujos modos de produção podemos nos apropriar para, assim, empreendermos uma analítica naquela história que nós diariamente fazemos (em diversos locais, mas, principalmente e com o foco aqui, na Educação).

É nesse sentido que percebemos algo potente perpassando a analítica foucaultiana, relacionado à contação da história cortazariana e que avança em outro espaço: não mais uma forma científica de analisar a literatura; muito menos uma forma literária de escrever sobre a ciência; mas dois modos de produzir saber. E o que gostaríamos mais do que produzir saber em nossas pesquisas em Educação? Mas, do ponto de ataque de nossa proposta, não determinado saber, não algum que ignore a dinâmica dessa Escola e dos processos educaticos em geral, mas, sim, aquele saber que é gestado partindo dessa própria variabilidade, desse próprio campo dinâmico, desse quadro cujo limite é sua borda e cujas séries que, aos poucos, vamos constituindo, têm por função compor a cena.

Assim, se nos deixamos mover por Foucault e pela possibilidade de construção de uma história que não se limita àquela das épocas, das continuidades, do homem sempre lá, do continuum de tempo, mas que nos joga de chofre contra crenças e, assim, nos faz suspender o que tomávamos como determinações naturais - como no conto recontado - e, conjuntamente, nos apropriamos de um outro modo de olhar e constituir a realidade com Cortázar, apostamos que os ensinamentos que trazemos destes dois pensadores podem contribuir para as nossas pesquisas em Educação e jogá-las em um espaço a compor, que a análise reconstitui a todo o momento. Entendemos que isso não é tarefa fácil, pois, para tal, é necessáiro que nos afastemos seja do sujeito transcendente, seja do tempo enquanto motor, seja das crenças que não têm por finalidade mais do que ignorar as mutabilidades que percebemos próprias a um espaço dinâmico. Nesse sentido, o que seria a pesquisa senão um trabalho crítico do pensamento sobre o próprio pensamento com o fim de desafiar a si mesma na produção de algo diferente? Isso exige esforço, coragem e uma boa dose de criatividade - pois então, encontremos 
esses elementos na interface entre literatura, saber e conhecimento e, se preciso, nos deleitemos na leitura dos contos ou das histórias foucaultianas e cortazarianas para nos mobilizarmos a (re)pensar a Educação.

\section{Notas}

${ }^{1}$ Conto La noche boca arriba, o qual o próprio Cortázar resume em seu curso de literatura na Universidade de Berkeley em 1980. Optamos por deixá-lo em espanhol devido à sonoridade, beleza e expressão das ideias de Cortázar, que, se traduzíssemos para o português, talvez perderíamos.

${ }^{2}$ Que, no caso de Foucault, ele jura não ser o autor (2008). 


\section{REFERÊNCIAS}

BRANCO, G. C. As resistências ao poder em Michel Foucault. Trans/Form/Ação, São Paulo, v. 24, p. 237-248, 2001.

CORTÁZAR, J. Julio Cortázar: Clases de Literatura - Berkeley, 1980. Santiago do Chile: Alfaguara, 2013.

DELEUZE, G. Foucault. São Paulo: Brasiliense, 2005.

DREYFUS, H.; RABINOW, P. Michel Foucault, uma trajetória filosófica: para além do estruturalismo e da hermenêutica. Rio de Janeiro: Forense Universitária, 1995.

FOUCAULT, M. História da Sexualidade 2: o uso dos prazeres. Rio de Janeiro: Graal, 1984.

1987.

As palavras e as coisas: uma arqueologia das ciências humanas. São Paulo: Martins Fontes,

História da Sexualidade 1: A vontade de saber. Rio de Janeiro: Graal, 1988.

Em defesa da Sociedade: curso no Collège de France. São Paulo: Martins Fontes, 1999.

. Sobre as maneiras de escrever a história. In:

Arqueologia das ciências e história dos

sistemas de pensamento. Rio de Janeiro: Forente Universitária, 2008. p. 62-77.

. Il potere, i valori morali e l'intellettuale: Un'intervista con Michel Foucault. Materiali Foucaultiani, v. 1, n. 2, p. 137-144, 2012a.

. Vigiar e punir: nascimento da prisão. Petrópolis: Vozes, 2012b.

Nietzsche, a genealogia e a história. In: Microfísica do Poder. São Paulo: Graal, 2013a. p. 55-86.

Verdade e Poder. In: Microfísica do Poder. São Paulo: Graal, 2013b. p. 35-54.

GALLO, S. Editorial: “O 'efeito Foucault' em Educação”. Pró-Posições, Campinas, v. 25, n. 2, p. 1521, ago. 2014.

OLIVEIRA, C. A vertigem da descontinuidade: sobre os usos da história arqueológica de Michel Foucault. História, Ciência, Saúde - Manguinhos, v. 15, n. 1, p. 169-181, mar. 2008.

SARAMAGO, J. O homem duplicado. São Paulo: Companhia das Letras, 2002.

VEIGA-NETO, A. A ordem das diciplinas. 1996. 322f. Tese (Doutorado em Educação) - Faculdade de Educação, Universidade Federal do Rio Grande do Sul, Porto Alege, 1996. 
A brief essay on time, subject and the ways of looking at history: Foucault and Cortázar
Keywords: Literature. Education. Knowledge.

\begin{abstract}
In this essay, different understandings in education field about the history's subject and time are addressed from Julio Cortázar's fiction literature and Michel Foucault's effective history. Starting with a cotazarian short story, time and subject are discussed as constituted in historical context. These cortazarian's ideas are articulated with foucaultian denial of subject doubles and time as a motor of history. Foucault and Cortázar are taken to problematize education field and to reconstruct time and subject conceptions.
\end{abstract}

\section{Bruno Pastoriza}

E-mail: bspastoriza@gmail.com

José Claudio Del Pino

E-mail: delpinojc@yahoo.com.br
Breve ensayo sobre el tiempo, el sujeto y los modos de ver la historia: Foucault y Cortázar

\section{Resumen}

Basado en la literatura fantástica de Julio Cortázar y en la propuesta de historia efectiva de Michel Foucault, este trabajo busca una manera diferente de pensar las relaciones entre el sujeto y el tiempo de la historia como elementos de los estudios en Educación. Comenzando con un cuento de Cortázar, se evidencia la posibilidad de leer de otro modo el tiempo en el que el cuento se desdobla y el sujeto que ahí se constituye. A partir de esas relaciones, se articulan las propuestas foucaultianas de aislamiento de los duplos que se refieren al sujeto y de la concepción del tiempo como motor de la historia. Se usa ambos los autores, por lo tanto, para problematizar el campo de las investigaciones en Educación y sus modos de comprender el tiempo y el sujeto que, por la mirada de esos autores, pueden reconstruirse.

Palabras claves: Literatura. Educación. Saber.

Enviado em: 30/11/2015

Versão final recebida em:

Aprovado em: 20/11/2016 